\title{
ICT-based Participatory Co-Creation of Urban Sustainability
}

\author{
Rita Pizzi \\ Department of Computer Sciences \\ University of Milan \\ SHuS - Sustainability and Human Security \\ Coordinated Research Center of the University of Milan \\ Via Celoria 18, Milan, Italy
}

\begin{abstract}
In the last decade Information and communication technologies (ICT) have become an important tool for socialization. More and more people build and maintain relationships through various social media and increasingly this influences the way they organize their daily lives and how they use the city and its spaces. However, the quality of public open spaces remains fundamental for the development of the cultural identity of a community, as they are important gathering points in the urban fabric and offer occasion for interactions and collaborations between generations and different ethnic diversities. People of all ages still need contact with nature and with other people, in order to develop different life skills, values, attitudes to health, satisfaction with their lives and responsibility towards the environment.

ICTs allow the development of strategies and tools to increase the quality of public open spaces, positively influencing participatory co-creation and the effects of social cohesion.

New ways of cooperative co-creation must be considered, in particular by using ICT to facilitate community interaction and engagement for the integration of diversity, and identifying social needs in open public spaces, aiming at the development of vibrant and accessible urban communities.
\end{abstract}

ICT gives also the opportunity to the urban communities to improve sustainability.

This paper presents best practices and new ICT solutions for enjoyable, inclusive, participatory, sustainable urban spaces.

\section{General Terms}

Social Networks, IoT, Smart Grid, Big Data.

\section{Keywords}

Sustainability, co-creation, public places, EV mobility, micro smart grid.

\section{INTRODUCTION}

More than half of the world's population lives today in urban areas. The quality of human life depends greatly on the quality of the urban environment, that in turn depends among other things on the quality of open public spaces accessible to the entire population.

Information and communication technologies (ICT) and mobile devices deeply affect different aspects of everyday life. As a result, the number of people using mobile devices in public spaces increases every day. The large number of tools that can be used for urban development is an unmissable opportunity to provide public spaces with a more digital dimension, where ICT can create a synergy between human beings and the environment. The network of open public spaces includes streets, squares, markets, community gardens, parks, playgrounds; each of these spaces plays a fundamental role in the social, cultural and economic life of the communities [1] .

The use of mobile devices is significantly changing the way people interact with other people and with the surrounding areas. Mobile devices can detect the users' location in their environment, and the geolocalized digital traces left by people in their daily activities can be used as data for statistics and metrics on the social behaviors of the users of public spaces [2].

Even if the examples of public open spaces that are transformed into "smart" spaces thanks to the use of ICT are increasingly present, much more it must be studied regarding the possible relations between open spaces and ICT . we can figure out that technology can improve safety, attractiveness, inclusiveness and comfort to the citizens [3]. It is possible to improve existing public spaces, giving users new tools to improve their experience. Furthermore the monitoring of the so-called user-generated data (UGD) allows the collection of a large amount of information useful to improve the existing open spaces and to design and manage the new ones properly.

The goal is therefore to reach a new paradigm for open spaces, characterized by a two-way exchange of data through ICT between space and citizens [4].

The monitoring, collection and analysis of fingerprints can be a valuable source of information for users, planners and stakeholders. Users can make their decisions on the place they will visit with greater awareness: this can lead to a better experience. On the other hand, planners and stakeholders can obtain a wide range of user comments to assess the attractiveness and usability of the places. Tourists visit the public space for a short period of time, looking for new unique experiences. The residents and those living in the neighborhood use the places in their daily life. Finally another category of users, which we can call the researchers, will look for specific information that the place can contain (e.g. naturalistic, archaeological or socio-cultural aspects). All three user groups still have common needs. Šuklje-Erjavec, Smaniotto Costa [5] have defined five different categories of needs: basic (available and safe space), emotional (pleasant area for personal perception), cultural (area that allows social interaction and contributes to the sense of belonging), spiritual (an area that offers "space" for reflection) and rational (an area that can be used for practical purposes).

In particular, social media play a fundamental role in the rereading of the concepts of time, space, social relationship, citizenship and identity [6]. This new way of communicating has the potential to improve communication with users and allow creative participation and education to the concept of community. Users can share news, expose opinions, needs and desires. The devices supported by GPS and GIS can 
provide information to planners, becoming a challenge to respond creatively to.

In the framework of the European funded project H2020 ERA-NET Cofund Smart Urban Futures called C3PLACES [7], ICT tools are under study to generate knowledge and know-how for a co-creation approach to be used to combine the use of ICT with novel potential in public spaces. The objective is the exploration of new dynamics of open spaces as a value-added service for the community, to expand our understanding of the functions of open public spaces, paying attention to stakeholders, local context and different social groups.

Methodologies and tools (such as web and mobile applications) for behavioral monitoring, social communication and interactions with different target groups in public spaces should be developed to obtain better and more systematic information and insights based on the use of opportunities and/or risks of ICT in use in public spaces.

To this end, a co-creation platform may provide a context for a pleasant interaction between citizens in public spaces, exploiting their different potential for co-creation. Its impact can be assessed with real case studies, providing aggregation and visualization of data related to the use of ICT applications in public spaces and linking to social media for extensive communication. The platform will be used as an innovative tool for the design of co-creative urban spaces.

An ICT platform based on a participatory framework gives also the opportunity to the urban communities to improve sustainability, improving EV mobility and using the sharing economy model to optimize the use of private renewable sources and power consumption.

\section{THE PRESENCE OF ICT IN PUBLIC SPACES}

There are several examples of digital open public spaces: interactive displays and totems in the cities, wi-fi availability in parks and squares, on-site tourist information, leisure activities, radio broadcasting, interactive artistic performances etc. Many researchers today work on ideas and applications on the theme of urban ecology, sustainable development and the effects of digital devices on them [8].

A field that already benefits greatly from a better interaction between ICT and public spaces is urban tourism [9], because it correlates to the quality of the places, to the information that is available and to the analysis of the opinions, motivations and behaviors of the visitors. Experiential tourism is today strongly linked to the digital approach. In fact, people who visit a new place begin their planning from the web, which offers the widest opportunity and makes user feedback the main criterion of decision [10]. During and after the stay, however, visitors send photographs and experiences via social networks to friends or other potential tourists [11]. The same procedure can also be followed by users of public spaces.

The spread of internet and wireless access have increased exponentially the connection requests. From this point of view, mobile communication devices are important, because while the connection was in the past mainly possible at home or at the workplace, now it is present in railway stations, airports, hotels, and in some more advanced cities is available in the main part of the streets.

Today, wireless local area networks (Wireless Local Area Network or WLAN) are located near streets, squares and parks, allowing laptops, smartphones or tablets to connect anywhere. The list of cities offering the basic service through Wi-Fi access points (hotspots, whose research is also supported by various websites and online travel guides) in public places is constantly growing in Italy and in Europe. Initially, this type of service was often entrusted to the same telecom operators, while today the management of public institutions is becoming increasingly widespread. Therefore, the availability of this technology and its largely free access can be seen as a social service provided by local administrations.

But this infrastructures should become a point of departure and not of arrival for the provision of public services, ideas, creativity, opportunities for co-creation and collective cultural and social exchange.

\section{ICT, PUBLIC PLACES AND CIVIL SOCIETY}

ICTs include a significant social component when they bring about changes in people's lifestyles, how they relate and communicate with each other. Social media are also a powerful instrument of collective action, as they enable communication and sharing of information at very low cost and high speed. These characteristics help mobilize the masses to gather in a certain place for demonstrations or protest actions.

The "flashmob", or self-organized mass meetings through social media, proved to be very efficient to organize different kinds of events that take place in public spaces: not only musical events, sports or entertainment, but also actions with public participation, such as strikes and demonstrations .

Tahrir Square in Cairo (Egypt) and Taksim Square in Istanbul (Turkey) have become famous throughout the world thanks to media events. The political movements of the so-called Arab Spring revolutions at the beginning of 2011 have been promoted through the use of modern means of communication. Internet, social media, blogs, were the triggers [12], which allowed a rapid diffusion of information, ideas and even live images (often unofficial) of the conflict areas. Not surprisingly, in these countries, regimes tend to limit the use of internet and social media .

Public spaces can actually be used in an unconventional manner through collective manifestations, creating a powerful media image. They have the potential to become democratic places able to encourage actions, based on the needs and aspirations of those who use them, embodying the central idea of the public dimension.

The adjective "public" should correspond to a recognition of quality and identification of public spaces as places for individual and collective expression. Public spaces can offer a number of advantages and opportunities for social interaction. The provision of quality public spaces should be a program and a political choice in the administrative planning of the Municipality, considering aspects such as security, accessibility, quality and design of these spaces. This framework therefore envisages participation not only for qualified professionals (landscape architects, urban designers) who are able to accept the challenge of developing convincing ideas of inclusive spaces, but also of political subjects to give priority to the inclusion of quality public spaces.

The challenge is how to make use of ICT to make public open spaces even more inclusive and to attract more people to live a healthier way of life. The quality of public spaces plays a decisive role, to convey a greater number of citizens to spend free time outdoors in accessible, safe, pleasant environments, 
a source of new forms of entertainment and socialization. Digital technologies add new levels of interaction and quality of life to open public spaces. The central challenge remains how to use digital technologies to transform our cities into interactive landscapes and urban places, encouraging the involvement and improvement of social environments, promoting sustainability, responsibility and knowledge of nature, city and citizenship in its cultural diversity.

The new technologies will probably lead to the creation of "2.0 public spaces", which will become intelligent spaces integrated by digital technologies [6]. The design of new spaces will have to contribute to the different needs of citizens in a co-creative way, that is by proposing and interactively receiving new ways of the use of spaces, in a virtuous exchange of creativity.

\section{ICT AND URBAN SUSTAINABILITY}

Improving the quality of urban spaces is certainly a task that never runs out.

But it is certain that the urban environment needs to provide healthy and livable places with a new high level of sustainability.

In urban areas, the problem of sustainability unfolds through a myriad of different problems and different possible solutions. Fundamental in this regard is the improvement of environmental quality and energy sustainability of cities and consequently of the quality of life of citizens.

\subsection{Interactive Participation for Sustainable Mobility}

The replacement of fossil-fuel vehicles with electric vehicles is a crucial element on which our ability to overcome the global emergence of air pollution and climate changes due to greenhouse gas emissions will be based in the coming years.

However, in many European countries there is a too slow increase in the diffusion of electric vehicles and recharging infrastructures.

A viable way to spread the mentality of sustainable mobility seems to be to promote, first of all, soft mobility (electric bikes and motorcycles, up to quadricycles) or "sustainable proximity mobility" that involves low costs, short journeys to and from local destinations, and fast charging, easily managed even from domestic plugs.

The current push of the Municipalities to the creation of widespread bike sharing networks it is a good example of the use of ICT for the improvement of public spaces: in this case the streets and the whole city, through the improvement of mobility and air quality. The popularity achieved by bike sharing shows that conscious and participatory citizens of this reality, through the appropriate use of geolocalized apps. In light of this finding, the expansion of this paradigm to electric soft mobility becomes more than a feasible hypothesis.

The spread of soft mobility can be encouraged by the creation of appropriate software and apps that can identify all the available charging stations and manage the sharing groups. It is also possible to identify sharing economy systems that connect users with recharging needs and private people or companies able to supply charging points.

In fact, the weak point that slows down the whole process of transition to decarbonised transport is the lack of infrastructures to support it. The widespread development of these infrastructures, per se of complex and long-term implementation, is held back by the slow pace of governmental and local political decisions, high costs and economic crisis.

But citizens themselves are able to accelerate and support this process by replacing it with the missing infrastructure. Mobile technology, and in particular the use of geolocalized apps, it is often able in a very short time to change from the bottom up consolidated situations that it would not be possible to change through top-down initiatives, in this case by the automotive companies or by supporting government actions.

\subsection{A Supportive Network for Sharing Charging Points}

An open project of the Department of Computer Science of the University of Milan, PEOPLE HAVE THE POWER [13], in collaboration with the Polytechnic University of Milan (Department of Architecture, Construction Engineering and Built Environment) proposes a geolocalized app that allows to find in the vicinity of your vehicle private buildings available to lend an electric outlet for charging electric vehicles, especially in yards, garages or parking spots.

As shown in the website demo, the app allows individuals, companies or commercial activities to register, describe their service, arrange payment via PayPal or credit card, or promote their charging spots with scores collection and exchange, discounts etc.

Users can use the recharge service while leaving the vehicle for commissions or for leisure, or during a holiday trip or when stopping for the night.

On the client side of the app, the car and the charging points available in the neighborhood or when the driver is planning to move are geolocalized (Figure 1). On the server side, the private owners of electricity suppliers available to provide the service can be enrolled. Suppliers must specify places, spaces, times and methods of service.

The app can make available links where to buy budget devices that transform the home outlet into a source of income: from economic models starting from 16 euros, to wall blocks, to multi-user posts. Alternatively, the supplier can independently purchase these devices from external dealers.

The service provider will therefore be able to make available a simple source of domestic electricity, with appropriate extensions and connectors, and to organize a control unit for fast refueling, a car parking spot in case of prolonged refueling, waiting room, possibility of overnight stay, and so on.

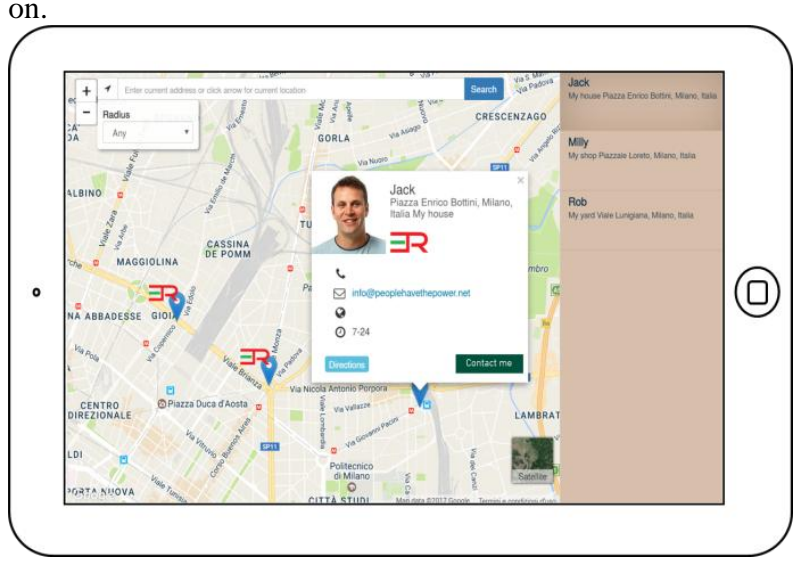

Figure 1: App interface that shows geolocalized private charging points 
Customers can view the various suppliers present at the required distance, contact them, confirm the service and pay via Paypal or credit card, or exchange collected scores or services (Figure 2).

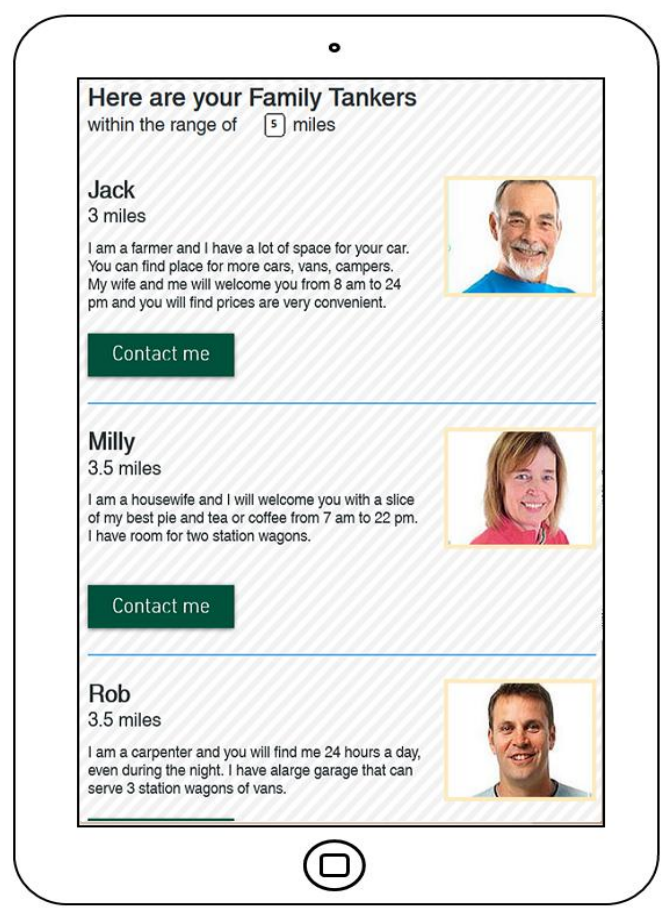

Figure 2: App interface that shows services and contacts of the private charging points

Also Bed and Breakfast, Hotels, Restaurants, Resorts, Shopping Centers , garages, workshops, companies with parking spaces, car sharing services, etc. will be able to add themselves to the app database by providing the service to their customers.

The creation of the described "social" platform can allow the sharing of these resources to registered users and will guarantee the monitoring of the reputation through feedback systems.

The platform can be integrated with a wider system of identification and booking of remote charging stations, with visualization for the availability of the recharge point, time and power engagement required, booking, etc. ;

After registration, through the geolocalization, the user can interface his vehicle with the supportive network of recharge offered by private users, condominiums, shops, public hubs that offer the free availability of their charging station against the availability to participate in the network with their own private charging station.

The user can also participate in a vehicle-sharing system at the local level. The vehicle can belong to a fleet set up for this purpose or the user can autonomously join spontaneous groups with his own vehicle.

The user interfaces with the "social" platform that allows the sharing of services to registered users and guarantees the monitoring of their reputation. Through the platform the user can access a series of additional functions such as the accumulation of scores through promotions, loyalty or gaming. The accumulated score will be evaluated in different ways. This allows the enabling of the innovative business model that provides for the cost of the service to be borne by different stakeholders, with a "sponsorship" fee against a return of image, allowing the end user to benefit from a free service.

The PEOPLE HAVE THE POWER idea crosses the scenario of the sharing economy with that of the green economy: the app is configured both as a source of income for many individuals or commercial activities and as a trigger for the diffusion, hitherto slowed down, of the electric car market and therefore for the abatement of harmful emissions. The system is an alternative to the public infrastructures reconversion to electric mobility and allows efficient management of recharging needs in municipal, free or paid parking spaces.

The value of the app it is global, because every nation is looking for alternative energy sources to oil and has set itself the goal of reducing harmful emissions. In particular, the app will be of immediate interest for Italy as well as for nations like China, in search of rapid solutions to reduce the dramatic rate of pollution.

\subsection{Micro Smart Grid for the Participated Energy Management}

The term Smart Grid refers to an electrical network that includes loads, accumulation points, generators and controllers able to communicate with each other in order to improve the efficiency of the energy system [14,15].

An electrical network becomes "intelligent" when it integrates traditional technologies with innovative digital solutions that make management more flexible through a more effective exchange of information.

With the introduction of solar panels and wind turbines, many homes are turning into micro-generation points. The connection of these micro-stations to the network is possible through Smart Grids (or - for now - local microgrids [16,17]) in order to control in real time the amount of energy used by the house and fed into the network.

The Smart Grid represents an opportunity of savings for citizens, who can balance their energy consumption on the basis of the variable hourly cost, and also enter in the network the energy produced from renewable sources.

It is also a well-established idea that electric vehicles will be a key element of the intelligent electricity grid.

The user can enter the excess energy online (Figure 3) by being paid or having a discount in the billing of the energy consumed: this is the so-called V2G protocol (vehicle to grid).

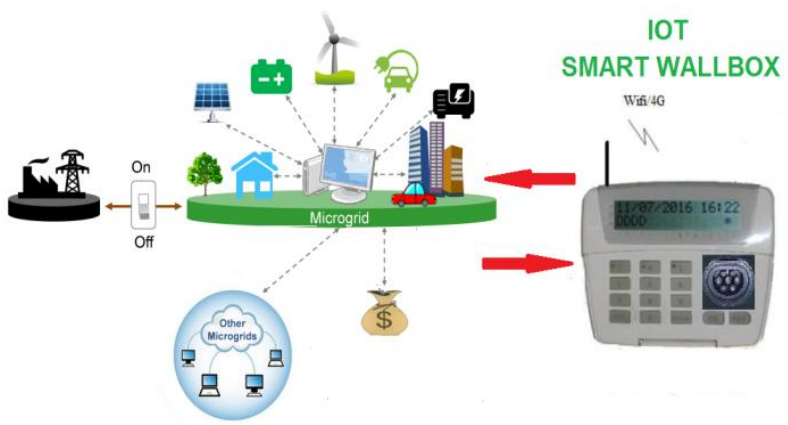

Figure 3: Micro Smart Grid managed by private users: the home device communicates with the renewable energy sources and EV vehicles optimizing power consuption 
It can therefore be created the possibility for the user to gain from inserting his vehicle into the electricity grid, reintroducing into the grid the accumulated energy taken in a previous time by the network itself or, possibly, by proprietary systems of energy storage, such as photovoltaic panels.

Once connected to the charging socket, the electric vehicle can in fact provide auxiliary services to the distribution network, improving its management and optimizing its operation.

The owners of an electric vehicle can be paid to feed energy into the grid at peak moments while the vehicle is parked and connected to the charging station. This technology can be realized by means of an IoT device integrated into a microgrid system for open public places (train or car stations, parking lots of sports centers, hospitals, hot spot locations with parking spots for bike/car public or private sharing, etc.), neighborhood or condominium.

From an economic point of view, the exchange of electricity between private individuals must be regulated according to regulations, referring not to the $\mathrm{kWh}$ exchanged, but to the value of the service provided.

Moreover, once available essential information for monitoring, optimization and exploitation of the electricity produced by the individual user, it will be possible gathering big data that can be analyzed for the economic benefit of citizens.

The device can also be integrated with the above mentioned app, by enabling its use for occasional users. This system is going to be developed in the frame of the INCASe project funded by the Lombardy Region.

\section{CONCLUSION}

The evolution of ICT leads to the often spontaneous cocreation, possibly guided by the institutions, of open "2.0" public places attractive, inclusive, aimed at enhancing sociocultural diversity and proposing new and engaging experiences.

The road to a greater degree of sustainability of urban spaces passes through the participatory action of citizens, facilitated by new technologies.

Among the infinite possibilities of evolution of the livability of urban spaces, a project is described that prefigures widespread and participatory availability of shared spaces, with a specific emphasis on the access to sharing and recharging points for electric mobility .

The sharing of electric vehicles and the V2G electricity supply can enhance the use of these spaces directly for the benefit of both the economic and the quality of life of citizens, also due to the reduced costs of construction and maintenance.

The "gentle revolution" leading to a more sustainable city in its open spaces thanks to the increasing of soft mobility, to the rapid transition to electric mobility and increased use of energy renewable by citizens may not be in a short time thanks to the only, slow and often contradictory position of the institutions: a participatory willingness is required by the citizens themselves. And to achieve this goal, the only but powerful tool available to the community is ICT , with its ability to connect in a simple and cheap way all citizens who wish to become available to a participatory co-creation of a better environmental quality of their own city. As a side effect, simultaneously a conscience of community will come to be consolidated, and manifest itself in other expressions of participatory co-creation, starting from the public spaces available to all citizens.

\section{ACKNOWLEDGMENTS}

I'd like to thank the co-founder of PEOPLE HAVE THE POWER, Andrea Mainini (Polytechnic University of Milan), together with all my co-partners of the mentioned INCASe and C3PLACES projects for sharing many ideas on the topics that gave raise to this paper.

\section{REFERENCES}

[1] Ioannidis, K., Smaniotto Costa, C., Šuklje-Erjavec, I., Menezes, M. and Bahillo Martínez, A. 2015. The Lure of CyberPark - Synergistic Outdoor Interactions between Public Spaces, Users and Locative Technologies. In Theona, I. \& Dimitris, C. (Eds.), Hybrid City 2015: Data to the People (272-281). Athens.

[2] Grauwin, S., Sobolevsky, S., Moritz, S., Gódor, I., and Ratti, C. 2015. Towards a Comparative Science of Cities: Using Mobile Traffic Records in New York, London, and Hong Kong. In Helbich, M., Jokar Arsanjani, J., Leitner, M. (Eds.) Computational Approaches for Urban Environments (363-387), Cham, CH: Springer International Publishing AG.

[3] de Lange, M. 2015. The Playful City: play and games for citizen participation in the smart city. Retrieved from http://cyberparks-project.eu/publications

[4] Kenna, T., and Vassi, A. 2015. Social Interactions and Encounters in Wireless Urban Public Spaces. In Proceedings of Conference of Irish Geographers. Technological imaginaries and the production of space. 21-24 May 2015, Belfast, IE.

[5] Šuklje-Erjavec, I., and Smaniotto Costa, C. 2015. CyberParks Challenges - Exploring the Relationships between Information and Communication Technologies and Urban Open Spaces. In Proceedings of Places \& Technologies (163-170). Nova Gorica, SI.

[6] Thomas, S. 2014. Cyberparks Will be Intelligent Spaces Embedded with Sensors and Computers. The Conversation. Retrieved from http://theconversation.com

[7] C3PLACES, H2020 ERA-NET Cofund Smart Urban Futures project, https://c3places.eu/

[8] Pizzi, R., Merletti De Palo, A., Co-Creazione partecipativa e Sostenibilità Urbana: il Ruolo della Cooperazione nell'Era dell'ICT 2018. In Fiamingo C., Bini V., Dal Borgo A. (Eds.), Città Sostenibili, Altravista Italy.

[9] Alvin Chua, A., Servillo, L. A., Marcheggiani, E., and Vande Moere, A. 2016. Mapping Cilento: Using Geotagged Social Media Data to Characterise Tourist Flows in Southern Italy. Tourism Management 57, 295310 .

[10] Girardin, F., Calabrese, F., Dal Fiore, F., Ratti, C., \& Blat, J. 2008. Digital Footprinting: Uncovering Tourists with User-Generated Content. IEEE Pervasive Computing, 7(4), 36-43.

[11] García-Palomares, J. C., Gutiérrez, J., \& Mínguez, C. 2015. Identification of Tourist Hot Spots Based on Social Networks: a Comparative Analysis of European 
Metropolises Using Photo-Sharing Services and GIS. Applied Geography, 63, 408-417.

[12] Gordon, S. 2017. Online Communities as Agents of Change and Social Movements. IGI Global, Hershey PA.

[13] PEOPLE HAVE THE POWER, Open Project, https://www.peoplehavethepower.net

[14] Xi, F., Satyajayant, M., Guoliang, X., Dejun, Y. 2012. Smart Grid - The New and Improved Power Grid: A Survey. IEEE Comm. Surveys \& Tutorials, 14(4) 1-38.
[15] Yutaka, O., , Haruhito, T., Tatsuhito, N., Kithsiri, M. L., , Jumpei, B. and Akihiko, Y. 2012. Autonomous Distributed V2G (Vehicle-to-Grid) Satisfying Scheduled Charging. IEEE Trans. On Smart Grid, 3(1) 559-564.

[16] Nordman, B. 2016. Local Grid Definitions. Lawrence Barkeley National Laboratory.

[17] Kim, D., Park, J., Jeon, D., Kim, S. and Won, Y. 2015. Microgrid's Strategic Planning in Kepco. 23rd International Conference on Electricity Distrib. Lyon. 